\title{
Sentimento atribuído pelo aluno de enfermagem no final da graduação
}

\author{
Cristiane Aparecida Silveira Monteiro ${ }^{1}$, Aline Graziele Firmino², \\ Daniela Aparecida Cruz Nascimento², Josemara Mirelle da Silva²
}

\begin{abstract}
RESUMO
Objetivos: compreender os sentimentos dos graduandos do último ano do curso de enfermagem durante o período de Estágio Supervisionado em Atenção Primária e Secundária, identificando suas expectativas, embasado em conhecimentos teóricos e práticos. Método: Pesquisa qualitativa, realizada através de aplicação de questionário semiestruturado, a partir de amostra composta por 22 alunos, matriculados na disciplina Estágio Supervisionado de Universidade Privada do Sul de Minas Gerais. Os dados obtidos durante a coleta de dados foram analisados e categorizados segundo análise de conteúdo segundo Minayo. Resultados: Constatou-se que os graduandos são em sua maioria jovens, do sexo feminino, possuem bolsa PROUNI ou FIES. Das falas emergiram diferentes sentimentos como aprendizagem, insegurança, ansiedade, satisfação, insatisfação e frustração. Conclusão: 0 trabalho pode contribuir na valorização dos sentimentos vivenciados pelos alunos durante os estágios por parte do professor. Sugere-se que esse reforce os sentimentos de confiança, de comprometimento com a profissão e reflexão com relação ao curso e especialmente, em relação ao paciente.
\end{abstract}

Descritores: Estudantes de Enfermagem; Estágio Clínico; Emoções.

\section{Assigned by the feeling of nursing student in final graduation}

\begin{abstract}
Objectives: To understand the feelings of the students of the final year of the nursing program during the Supervised Internship in Primary and Secondary Care, identifying their expectations, based on theoretical and practical knowledge. Method: Qualitative research, applied through a semi-structured survey, and a sample of 22 students enrolled in the supervised internship course in a private university situated in the south of Minas Gerais. The data obtained during the collection of data were analyzed and categorized according to content analysis Minayo. Results: It was found that undergraduates are mostly young, female, have PROUNI or FIES scholarship. From the speeches emerged as learning different feelings, insecurity, anxiety, satisfaction, dissatisfaction and frustration.. Conclusion: The work can contribute to the appreciation of the feelings experienced by students during the stages from the teacher. It is suggested that this reinforces the feelings of trust, commitment to the profession and reflection about the course and especially in relation to the patient.
\end{abstract}

Descriptors: Nursing Students; Clinic Internship; Feelings.

${ }^{1}$ Doutora em Enfermagem pela Escola de Enfermagem de Ribeirão Preto, Universidade de São Paulo (USP), São Paulo, SP, Brasil.

${ }^{2}$ Graduanda em Enfermagem na Pontifícia Universidade Católica de Minas Gerais (PUC Minas), Poços de Caldas , MG, Brasil. 


\section{Introdução}

É essencial para um bom aprendizado, uma base teórica e conhecimentos que são adquiridos principalmente por meio de uma graduação, que o aluno desenvolve afetividade e uma melhor comunicação e compreensão. Aenfermagem é uma profissão que vem se expandindo com o passar do tempo, não só em nosso País, como em todo o mundo, devido às mais diversas necessidades da saúde, necessitando assim, de profissionais capacitados e que ofereçam um atendimento de qualidade ${ }^{1}$.

Para os concluintes do ensino médio, este é um momento de escolhas profissionais no qual se configuram mudanças críticas em sua vida. Essas mudanças, se não forem bem amparadas e pensadas, podem acarretar conflitos relacionados à entrada no mundo adulto e na sua futura ocupação $0^{2,3}$.

A escolha por ingressar em uma graduação de enfermagem nem sempre é realizada por aqueles indivíduos que já atuam na área. $O$ graduando pode ter sua vocação influenciada por vários fatores como experiências pessoais, familiares, escolares ou profissionais, já que a escolha profissional é multifatorial e está interligada às experiências de vida cotidiana e às perspectivas de futuro ${ }^{4}$. Porém, a procura dos jovens pela profissão, tem ganhado cada vez mais espaço, devido ao aumento do número de vagas para atuação na área da saúde ${ }^{3}$.

O primeiro contato com a profissão propiramente dita pode ser uma vivência difícil. É importante o papel do professor, responsável por incentivar o graduando a buscar o conhecimento de forma mais consciente e responsável, auxiliando no bom relacionamento junto à equipe ${ }^{5}$.

Na formação do enfermeiro, além dos conteúdos teóricos e práticos desenvolvidos, os cursos têm como exigência a disciplina de Estágio Supervisionado em Atenção Primária e Secundária em sua grade curricular, com duração aproximada de 500 horas, inserindo o graduando nos estabelecimentos de saúde como hospitais conveniados, ambulatórios e Rede Básica de Serviços de Saúde ${ }^{6}$.

Conhecer as expectativas desses alunos e o sentimento atribuído por eles ao final da sua graduação é de suma importância para os alunos ingressantes no curso e para os professores que lecionam disciplinas práticas, permitindo um aprendizado participativo e possibilitando diferentes formas de atuação nos campos de estágio 5 .

\section{Histórico da formação em enfermagem}

A história da Enfermagem Moderna no Brasil, teve início em 1923, a partir da sua implantação segundo o modelo Norte Americano, pela Escola Anna Nery, considerada escola padrão, redimensionando todo modelo de enfermagem no Brasil, apesar de anteriormente, em 1890, a Escola de Enfermagem Alfredo Pinto (EEAP), no Rio de Janeiro, ter sido considerada a primeira escola de enfermagem que formava profissionais para atuarem no Hospício Nacional dos Alienados ${ }^{7}$.

Em 1926, foi criada a Associação Nacional de Enfermeiros Diplomados Brasileiros, atual Associação Brasileira de Enfermagem (ABEn), que filiou-se em 1929 ao Conselho Internacional de Enfermagem. Logo após, aliada ao Ministério da Educação e Saúde em 1930 e ao Ministério do Trabalho Indústria e Comércio em 1931, afixou que todas as escolas de Enfermagem deveriam funcionar dentro dos padrões da Escola Anna Nery Decreto n 20.109/316,8. Já a centralização do ensino em nucleos universitarios ocorreu após a promulgação da Lei 775 em $1949^{9}$.

O exercício profissional da Enfermagem no Brasil foi regulamentado pela lei 2.604/55. A lei 2.822/56 dispôs sobre 0 registro de diploma do enfermeiro expedido até o ano de $1950^{8}$. A lei 2.995/56 passou a exigir de todas as escolas o nível secundário completo ou equivalente dos candidatos que pretendiam ingressar no curso de enfermagem e no ano seguinte, há proposta do ensino a nível superior. A lei 4.024/56 dispôs sobre Diretrizes e Bases da Educação Brasileira (LDB) ${ }^{10}$.

No ano de 1973, foi criado o Conselho Federal de Enfermagem (COFEN), órgão fiscalizador do exercício profissional da Enfermagem em todo o território nacional, através dos Conselhos Regionais de Enfermagem (COREN) localizados nos estados brasileiros. O Sindicato e a Associação Brasileira de Enfermagem (ABEn) entidades reinvidicatória e cultural respectivamente completaram o rol das entidades de educação e defesa dos enfermeiros brasileiros ${ }^{9}$.

Com a lei 6.229/75 do Sistema Nacional de Saúde foi legitimada a pluralidade institucional no setor, identificando a Previdência Social como responsável pela assistência individual e curativa e o Ministério da Saúde por intermédio das Secretarias, pelos cuidados preventivos e de alcance coletivo. (paulus, 2006). Desde 1985 até 2001, a ABEn junto com a Comissão de Especialistas de Enfermagem da Secretaria da Educação Superior do Ministério da Educação, definiram os parâmetros e diretrizes básicas norteadores da formação da enfermagem no Brasil ${ }^{10}$.

A lei 7.498/86 regulamentou o exercício profissional dos enfermeiros, trazendo grandes avanços para a profissão. Concomitante a aprovação da Lei, aconteceu a $8^{\text {a }}$ Conferência Nacional de Saúde que culminou na proposta que mais 
tarde se tornaria o Sistema Único de Saúde, baseado nas diretrizes de descentralização, universalização, equidade, integralidade, qualidade da atenção e humanização do atendimento ${ }^{11}$.

As Diretrizes Curriculares Nacionais foram criadas para os cursos de graduação em Enfermagem através da Resolução CNE/CES $n^{0} 3$, de 7 de novembro de 2001, que direciona o desenvolvimento e avalição dos projetos pedagógicos e a política de formação superior para a área de Enfermagem no Brasil ${ }^{6}$.

A disciplina de Estágio Supervisionado no curso de enfermagem é um exercício da liberdade e de sua autonomia, envolvendo responsabilidades e compromissos dos alunos, com as suas próprias decisões e atitudes. Busca desenvolver a sua autodeterminação e autoconfiança resultando assim segurança para agir de maneira muito próxima ao papel do Enfermeiro na área da prática profissional ${ }^{13}$.

O estágio prevê a participação, do professor da instituição de ensino, e um supervisor por parte concedente no acompanhamento efetivo do estágio. As Diretrizes Curriculares Nacionais do Curso de Graduação em Enfermagem buscam assegurar a efetiva participação dos Enfermeiros do serviço de saúde, onde desenvolverá as atividades, de acordo com programação e o processo de supervisão do aluno no estágio curricular supervisionado ${ }^{6}$.

Outra questão é a importância de conciliar no espaço curricular os ideais de humanização da assistência e os imperativos da conduta ética, com ações de capacitação do aluno para atuação no mercado de trabalho, onde o papel do enfermeiro é cada vez mais voltado para a o gerenciamento de processos e para procedimentos tecnológicos de enfermagem ${ }^{14}$.

O cuidado enquanto essência tem sido valorizado tanto no que se refere ao processo de cuidado individual quanto coletivo ${ }^{15}$.

A universidade, enquanto instituição de ensino e formadora de profissionais é de suma importância, uma vez que contribui para o acadêmico durante todo o curso, principalmente no que se refere à importância do cuidado da enfermagem, pois é através do que se foi aprendido, que o futuro profissional vai ter o seu primeiro contato com o paciente, construindo uma relação de ajuda e satisfação das necessidades de forma harmoniosa e benéfica para ambas as partes ${ }^{15}$.

Destaca-se também, a importância de uma comunicação entre o professor orientador e 0 aluno, para que nas dificuldades durante as atividades da prática profissional, o graduando possa contar com o apoio do seu orientador, não gerando o sentimento de desânimo ou desistência ${ }^{16}$.

As Diretrizes Curriculares de Enfermagem, no artigo $3^{\circ}$, explicitam que na ausência do professor orientador da instituição de ensino é vedado ao Enfermeiro exercer, simultaneamente, a função de supervisor de estágios e as atividades assistenciais e ou administrativas para as quais estiver designado naquele serviço ${ }^{16}$.

Através desta oportunidade acadêmica, o aluno tem um forte impacto na percepção da realidade profissional da enfermagem, gerando um envolvimento com a assistência em sua dimensão teórica, filosófica, ética, política e administrativa, que se transforma na experiência de caminhar sobre as próprias pernas ${ }^{6}$.

\section{Metodologia}

Trata-se de uma pesquisa descritiva do tipo qualitativa. A pesquisa qualitativa se preocupa com as ciências sociais a um nível de realidade que não pode ser qualificado e trabalha com o universo de significações, crenças, valores e atitudes ${ }^{17}$.

O estudo foi desenvolvido em uma universidade privada do Sul de Minas Gerais que oferece 12 cursos de Graduação e conta aproximadamente com 7.000 alunos matriculados e uma média de 720 alunos ingressantes por semestre.

O curso de Enfermagem iniciou-se no ano de 2005 e formou a sua primeira turma no primeiro semestre do ano de 2009. Este curso tem como objetivo a formação de profissionais com visão generalista, buscando constantemente conhecimentos e com a finalidade de melhor atender a comunidade que estão inseridos, formando profissionais comprometidos com o bem estar físico, mental e sócio espiritual da população e desenvolvendo ações de enfermagem tanto no setor publico quanto no setor privado.

A população foi constituída por todos os alunos do curso de Enfermagem, regularmente matriculados e cursando a disciplina de Estágio Supervisionado em Atenção Primária e Secundária no $8^{\circ}$ período do $2^{\circ}$ semestre do ano de 2013.

$O$ instrumento utilizado para a coleta de dados foi um questionário semiestruturado com perguntas abertas, aplicado em sala de aula, após esclarecimento prévio dos propósitos do estudo pelos pesquisadores e aceite dos pesquisados por meio da assinatura do termo de consentimento livre e esclarecido (TCLE), conforme Resolução 466/12 do Conselho Nacional de Saúde (CNS). 
O questionário foi aplicado em dois momentos: antes da realização do estágio (mês de agosto/2013) e dois meses após o inicio do mesmo (outubro/2013). Foi considerado critério de inclusão, os alunos que estavam regularmente matriculados e cursando a disciplina de Estágio Supervisionado em Atenção Primária e Secundária e como critérios de exclusão alunos que não cursavam esta disciplina.

Os dados foram analisados e categorizados segundo análise de conteúdo em três etapas. A primeira foi a ordenação dos dados, que englobou as seguintes etapas: a transcrição dos dados em sua íntegra; a leitura exaustiva, que possibilitou a tomada de decisão sobre quais deles efetivamente estavam de acordo com os objetivos da pesquisa; a organização dos dados, onde foi possível estabelecer os núcleos de sentido. Na segunda etapa, os dados foram classificados ou categorizados. A categorização é um procedimento de agrupar dados, considerando a parte comum existente entre eles. A terceira etapa foi a de análise final, procurando estabelecer as relações entre os dados e a realidade, à luz da literatura consultada ${ }^{17}$.

Com a finalidade de manter sigilo das informações e identidade dos profissionais entrevistados, optou-se por identificar os alunos entrevistados por letras A1, A2 e assim sucessivamente.

Quanto aos aspectos éticos da pesquisa, o projeto foi submetido à apreciação e aprovado pelo Comitê de Ética em Pesquisa da PUC Minas, buscando-se respeitar as exigências da Resolução do CNS n0666/12 (CAAE: 0118.0.213.000).

Como limitações deste estudo, destaca-se a não avaliação de outras variáveis como o fato da universidade ser privada influenciou nos sentimentos e expectativas.

\section{Resultados e discussão}

Primeiramente, foram entrevistados 22 alunos matriculados na disciplina de Estágio Supervisionado em Atenção Primária e Secundária, baseado em dados psicossociais.

Quanto ao sexo, 20 (91\%) são mulheres e 2(9\%) são homens. Esses dados coincidem com os diversos outros estudos que relatam o caráter feminino da enfermagem, demonstrando a característica histórica da enfermagem, profissão exercida quase que exclusivamente por mulheres desde os seus primórdios ${ }^{18}$.

A literatura registra predominância de trabalhadores nos hospitais do sexo feminino, principalmente na enfermagem, é explicada culturalmente, pois a assistência e higienização dos doentes são consideradas como extensão do trabalho da mulher. Entretanto, outros estudos recentes têm relatado o aumento do número de ingressantes na graduação do sexo masculino ${ }^{18,19}$.

Em relação à idade, verificou-se que nove (40,9\%) alunos estão entre a faixa etária de 18 a 21 anos, seguida por sete $(31,8 \%)$ na faixa de 22 a 25 anos e os demais $(27,3 \%)$ tinham mais de 25 anos. Estes dados reforçam as informações obtidas em outros estudos em que a maioria dos alunos da enfermagem são jovens ${ }^{5}$.

A presença de graduandos mais jovens pode ser um ponto positivo, pois estes têm oportunidades de se aperfeiçoar mais cedo, tendo uma visão maior de crescimento e sucesso na carreira. Contudo, terão que enfrentar os desafios, medos, inseguranças e estresse da profissão precocemente levando a dúvidas sobre sua escolha profissional ${ }^{5}$.

Com relação ao número de filhos, 21 (95,5\%) dos alunos não tem dependentes. No geral, as mulheres priorizam a formação profissional e a inserção no mercado de trabalho, considerando difícil conciliar as atividades acadêmicas e a vida privada ${ }^{3}$.

O estado civil predominante foi solteiro, sendo $18(82 \%)$ dos graduandos. $O$ resultado deste estudo revelou minoria quatro $(18,2 \%)$ casados, evidenciado pelo fato de que as mulheres estão priorizando os estudos e sua inserção

no mercado de trabalho deixando o casamento para mais tarde ${ }^{3}$.

Quanto à renda familiar dos graduandos, $13(59,1 \%)$ tem renda de 1 a 3 salários mínimos, $6(27,9 \%)$ tem renda acima de 5 salários mínimos e $3(13,6 \%)$ tinham renda familiar menor que 1 salário mínimo. Pode-se considerar que para 0 graduando estudar os seus familiares precisam ter um maior rendimento ${ }^{3}$.

Nota-se que a maioria dos jovens mora com os pais $10(4,5 \%)$ e $8(36,4 \%)$, moram em repúblicas ou sozinhos, uma vez que a saída de casa é um momento marcante para aqueles que deixam suas famílias para morar em outras cidades ${ }^{19}$.

Após a apresentação e discussão dos dados psicossociais, foram analisadas questões educacionais e profissionais destes alunos estagiários.

A primeira opção no vestibular foi pelo curso de enfermagem 18 (81,8\%), que além da vocação, foi considerado a melhor opção do mercado de trabalho em saúde, mostrando que o estudante ingressante está preocupado em se preparar para uma área profissional promissora ${ }^{20}$. 
O desenvolvimento vocacional advém de um processo contínuo que decorre de diversas experiências pessoais, escolares e profissionais que proporciona a imersão das potencialidades, dos interesses e das necessidades que permearão a conduta vocacional do indivíduo ${ }^{21}$.

Do total de pesquisados, 5 (22,7\%) tinham experiência na área. Dentre os diversos motivos que levam os trabalhadores da área de enfermagem a optar pela graduação observa-se que este é um curso menos seletivo, permite a ascensão profissional, melhora o conhecimento científico e consequentemente, a possibilidade de mudar seu status dentro da equipe ${ }^{21}$.

Do total de pesquisados, 16 alunos (72,7\%) não possuem experiência na área, porém trabalham em outra atividade profissional.

Referente à jornada de trabalho dos acadêmicos oito $(36,4 \%)$ trabalhavam oito horas diárias, cinco $(22,7 \%)$ trabalhavam de 20 a 40 horas semanais e nove $(40,9 \%)$ não trabalhavam.

Os alunos também foram questionados acerca dos dados sobre bolsa auxílio de estudos do Programa Universidade para Todos (PROUNI) e Financiamento Estudantil (FIES), além de descontos obtidos quando participam de projetos Programa Institucional de Bolsas de Iniciação Científica (PROBIC) e Fundo de Incentivo a Pesquisa (FIP).

Dos graduandos entrevistados, 8 (36,4\%) possuíam bolsa PROUNI, 6 (27,3\%), possuíam bolsas do PROUNI e FIES, o que demonstrou que a bolsa é complementada juntamente com o financiamento, uma vez que são ofertadas bolsas integrais e parciais de 25 e $50 \%$ e o FIES só é pago ao final do curso ${ }^{22}$. Ainda, 4 (18,2\%) tinham bolsas de Iniciação Científica ou de Extensão.

Os demais, $18,2 \%$ dos alunos, não possuíam nenhum tipo de bolsa por não se encaixarem nos critérios de elegibilidade para o PROUNI, uma vez que o programa possui público alvo: estudantes carentes, concluintes do ensino médio em escola pública, participação no ENEM e uma renda per capita familiar de 1 a 3 salários mínimos ${ }^{16}$.

No total, 9 (40,9\%), tem bolsas de Iniciação Cientifica, 4 (18,2\%) bolsas dos projetos de extensão FIP/PROBIC e 9 $(40,9 \%)$ não participaram de qualquer projeto.

Em um segundo momento, após questionamento "sobre expectativas e sentimentos quanto ao inicio da disciplina de Estagio Supervisionado em Atenção Primária e Secundária”, emergiu a categoria positiva (aprendizagem) e as categorias negativas (insegurança, ansiedade e medo).

\section{Aprendizagem}

Aaprendizagem é um processo de difícil implantação e que leva anos para que os acadêmicos se aprimorem. Conforme a Diretriz Curricular, o estágio de enfermagem é realizado no último ano da graduação e sendo assim, os graduandos estão mais preparados para realizar as técnicas, abordagem e contato com paciente ${ }^{6}$.

[...] espero ampliar meu conhecimento sobre a abordagem e a realização correta das técnicas no paciente. Adquirir experiência e prática em todos os campos de estágio. (A1)

[...]acredito que o estágio será um campo onde aprendemos muito, conheceremos técnicas, vivenciaremos realidades diferentes e isso será muito bom para a experiência profissional de cada um de nós. (A2)

Ao desenvolver sua autonomia, a experiência facilita muito ajudando relacionar o conteúdo teórico ao prático, em um processo contínuo de descobertas, criando espaço de participação em tomadas de decisão e aplicando o conhecimento no contexto da prática de enfermagem, como propósito as ações educativas da saúde, de forma comprometida para enfrentar os desafios do cotidiano ${ }^{10}$.

\section{Insegurança}

Os graduandos, ao iniciarem o seu primeiro estágio se sentem inseguros no relacionamento com paciente, por isto para amenizar a situação, o desenvolvimento da comunicação se faz cada vez mais necessário e somente assim é possível continuar prestando cuidado competente e humanitário ${ }^{23}$.

Em contrapartida, a disciplina de estágio mostra aos acadêmicos, uma visão assistencial multidimensional, contribuindo para sua maturidade acadêmica-profissional, fundamentada na experiência prática, proporcionando ao estudante segurança e postura crítica diante dos conflitos cotidianos da profissão $0^{13,16}$.

[...] sentimento de medo de não conseguir realizar tudo o que aprendi por causa da insegurança e inexperiência. (A20) 


\section{[...] insegurança com relação às técnicas por falta de prática.(A21)}

[...] um pouco de ansiedade, misturada com insegurança mesmo já sendo da área, o sentimento de coisas novas ainda me faz sentir um pouco de medo. Conseguir suprir minhas, expectativas e processar realizar um trabalho humanizado e com dedicação.(A17)

\section{Ansiedade}

Com o estilo de vida atual, a ansiedade entre a população vem aumentando cada vez mais, sendo comum entre os indivíduos, causando grande impacto sobre o bem estar e as atividades diárias das pessoas, sendo por esse motivo, alvo de estudos entre vários grupos de indivíduos e a enfermagem é dos grupos que vem sendo observado, pois é uma das classes que mais possui esses tipos de transtornos ${ }^{24}$.

As pessoas passam por vários tipos de transtornos, sendo um deles a ansiedade, causando um impacto relevante no bem estar físico e até mesmo nas atividades diárias das pessoas, sendo alvo de estudos entre vários grupos de indivíduos ${ }^{24}$.

\section{[...] experiência nova, muita expectativas, muitas dúvidas, ansioso quanto aos procedimentos. (A3) \\ [...] estou ansioso, pois será uma experiência nova, onde irei colocar em prática tudo que aprendi na teoria.(A6)}

A formação acadêmica está mais centrada em conhecimentos técnico-científicos direcionados especialmente ao atendimento das necessidades daqueles que serão assistidos, sem considerar a pessoa que os assiste. Outro ponto é que a trajetória acadêmica é permeada por vários sentimentos, dentre eles a ansiedade, que aparecem em função das experiências ocorridas ao longo da mesma ${ }^{23}$.

\section{Medo}

A entrada brusca dos estudantes em uma realidade desconhecida desencadeia sentimentos que interferem de modo negativo no aprendizado, sendo imprescindível que o docente que atua diretamente em campo de estágio, principalmente no estágio inicial, incorpore atitudes de compreensão do outro ${ }^{23}$.

[...] tudo novo, estranho, diferente de tudo que já vi [...] tenho medo [...] medo de não conseguir fazer e aprender.(A9)

$\mathrm{Na}$ segunda categorização, ao serem questionados sobre "Ao iniciar a disciplina de Estágio Supervisionado, as expectativas e sentimentos foram correspondidas com o que se esperava?" e sobre "Como os seus sentimentos interferiram no seu desempenho?", emergiram as seguintes categorias: satisfação, insatisfação e frustração.

\section{Satisfação}

A satisfação é um fator que deve ser explorado e se torna um indicador da qualidade tanto da sua formação quanto da prestação de serviço. 0 indivíduo satisfeito se envolve em um processo de avaliação da adequação da estrutura pedagógica do curso e dos aspectos intervenientes desse processo de formação acadêmica assim como colocam em prática o que melhor adquiriu na sua formação ${ }^{25}$.

[...] a satisfação no campo de estágio foi importante para mim, pois no decorrer dos dias, fiquei mais confiante para realização de procedimentos, sem a supervisão dos professores. (A15)

[...] eu me sinto muito confiante e determinado nos meus objetivos no estágio. Foi uma experiência nova, pois fui muito bem preparado teoricamente. (A18)

\section{Insatisfação e Frustração}

O grau de insatisfação de uma equipe de trabalho reflete nos atendimentos prestados, pois este desconforto pode levar os profissionais à diminuição da produtividade e à quebra da comunicação entre os membros da equipe ou entre a equipe e a direção $0^{26}$. 
[...] as minhas expectativas e sentimentos foram pouco correspondidos por não ter tido oportunidade de realizar todas as atividades. Senti-me desanimada, mas não deixei que isto interferisse no meu desejo de aprender. (A1)

[...] sempre esperamos mais. A realidade na prática é outra, pois na faculdade a gente vê de uma forma e quando caímos na prática, observa-se as reais dificuldades, e isso frustra quem está começando agora. (A11)

Afrustração vem como consequência do não atendimento das expectativas dos pacientes por parte do aluno gerando sentimentos de ociosidade no campo de estágio, causando assim, uma situação desconfortável tanto para si próprio, quanto para o professor ${ }^{23}$.

Há ainda o fato de que a atividade assistencial, que exige o contato direto dos profissionais da saúde com o ser humano, é, ao mesmo tempo, fonte de gratificação e de frustação. De um lado há o sentimento de sentir-se competente e receber conhecimento e do outro a dor, o sofrimento, comportamentos depressivos e hostis ${ }^{23}$.

[...] é difícil porque às vezes você não tem o que falar para o paciente [...] e isso me frustrava, não poder fazer nada, [...] estar impotente. (A9)

Portanto, é fundamental criar condições para que o aluno possa ser ouvido e compreendido, ao falar de seus sentimentos em relação a si mesmo e em relação ao cliente, bem como um ambiente propício ao aprendizado.

\section{Considerações Finais}

Constatou-se que a maioria dos graduandos é jovem, do sexo feminino, possuem bolsa do PROUNI ou FIES e que não exercem nenhuma atividade remunerada na área.

Identificou-se os mais diversos sentimentos atribuídos pelos graduandos de Enfermagem no campo da prática dentre eles aprendizagem, insegurança, ansiedade, satisfação, insatisfação e frustração, considerando tratar-se de um momento de conflito na vida do aluno no que se refere às experiências, busca-se estratégias para lidar com os sentimentos em campo de estágio.

Constatou-se que os sentimentos de ansiedade dos alunos são ocasionados, especialmente, pela sensação de insegurança diante das demandas cotidianas inerentes ao exercício profissional. Considerando que o estágio é indispensável na construção da identidade profissional e que o envolvimento humano não pode ser sistematizado, deve buscar-se um contato mais intenso para gerar o conhecimento.

O resultado deste trabalho pode ser uma futura contribuição com acadêmicos e ingressantes e como sugestão para os professores de estágio para que reforcem sentimentos de confiança, de comprometimento com a profissão e reflexão com relação ao curso.

\section{Referências Bibliográficas}

1. Lazzari DD, Jacobs LG, Jung W. Humanização da assistência na enfermagem a partir da formação acadêmica. Rev Enferm UFSM 2012 Jan/Abr;2(1):116-24.

2. Luchesi LB, Mendes IAC, Shiniyashiki GT, Costa Junior ML. Elaboração de instrumento para análise da imagem do enfermeiro frente a alunos do ensino médio. Rev Esc Enferm USP 2009 June;43(2):272-8.

3. Lima CA, Vieira MA, Costa FM. Caracterização dos estudantes do curso de graduação em Enfermagem de uma universidade pública. Rev Norte Min Enferm 2014;3(2):33- 46

4. Santos RS, Pereira LMS, Marques FM, Costa NCF, Oliveira PS. Perfil socioeconômico e expectativa docente de ingressantes no Curso de Licenciatura em Ciências Biológicas. Rev Eletrônica Educ. 30 de agosto de 2014;8(2):293-303. 5. Silva GA, Correa RJV, Correa R, Silveira CA, Paiva SMA. Feelings experienced by nursing students during supervised training. Journal of Nursing UFPE on line 2011, 5(7):9-19.

6. Conselho Nacional de Educação. Câmara de Educação Superior. Resolução CNE/CES n.3, de 07 de novembro de 2001. Institui as Diretrizes Curriculares Nacionais do curso de graduação em enfermagem. Diário Oficial da República Federativa da União. Brasília, 09 nov. 2001. Seção 1, p.37. 
7. Moreira A, Oguisso T. Profissionalização da enfermagem brasileira. Rio de Janeiro: Guanabara Koogan; 2005.

8. Brasil. Decreto lei n. 20.109, de 15 de junho de 1931. Regula o exercício da Enfermagem no Brasil e fixa as condições para a equiparação das Escolas de Enfermagem e Instruções Relativas ao Processo de Exame para Revalidação de Diplomas. Diário Oficial República Federativa do Brasil 1931; 10516.

9. Geovanini T et al . História da enfermagem: versões e interpretações. Rio de Janeiro: Revinter; 2010.

10. Silveira CA, Paiva SMA de. A evolução do ensino de enfermagem no brasil: uma revisão histórica. Ciênc Cuid Saúde. março de 2011;10(1):176-83.

11. Souza GCA, Costa ICC. O SUS nos seus 20 anos: reflexões num contexto de mudanças. Saude soc 2010 Sep;19(3):509-17. 12. Brasil. Ministério da Educação. Lei 9.394 / 96, de 20 de dezembro de 1996. Lei de Diretrizes e Bases da Educação Nacional. [internet] 1996 [acesso em 2013 Mai 05]. Disponível em: http://portal.mec.gov.br/seed/arquivos/pdf/tvescola /leis/lein9394.pdf 13. Evangelista DL, Ivo OP. Contribuições do estágio supervisionado para a formação do profissional de enfermagem. Rev Enferm Contemp 2014 Dez;3(2):123-30.

14. Esperidião E, Silva NS, Caixeta CC, Rodrigues J. A Enfermagem Psiquiátrica, a ABEn e o Departamento Científico de Enfermagem Psiquiátrica e Saúde Mental: avanços e desafios. Rev bras enferm 2013 Sep;66(spe): 171-6.

15. Gonçalves CC, Macêdo CS, Piancó IMFG, Almeida IB, Dantas Neto FA. Ética no cuidar em enfermagem: uma proposta a ser construída na graduação. In: Anais do Congresso Brasileiro dos Conselhos de Enfermagem;2011 mar; Curitiba. Disponível em: http://189.75.118.67/CBCENF/sistemainscricoes/arquivos Trabalhos//26530.pdf

16. Lopes Chaves ER, Prado Simão TO, Oliveira, IS, Prado de Souza I, Hollanda lunes D, Alves Nogueira D. Avaliação da autoestima em estudantes de enfermagem de uma universidade do sul de Minas Gerais (Brasil). Investigación y Educación en Enfermería 2013;31(2):261-9

17. Minayo MCS. O desafio do conhecimento: pesquisa qualitativa em saúde. 12 ed. São Paulo- Rio de Janeiro: Hucitec/Abrasco; 2010.

18. Dias HCVB, Paiva KCM. Formação e desenvolvimento de competências Profissionais na Enfermagem: percepções dos professores. Rev Min Enferm 2009;13(3):372-80.

19. Soares AB, Poube LN, Mello TVS. Habilidades sociais e adaptação acadêmica: um estudo comparativo em instituições de ensino público e privado. Aletheia 2009 Jun; (29):27-42.

20. Donati L, Alves MJ, Camelo SHH. O perfil do estudante ingressante no curso de graduação em enfermagem de uma faculdade privada. Rev enferm UERJ. 2010 Jul-Set [acesso em 2013 out 20]; 18 (3): 446-50. Disponível em: http://www. facenf.uerj.br/v18n3/v18n3a19.pdf

21. Barlem JG, Geri T, Lunardi VL, Bordignon SS, Barlem ELD, Lunardi Filho WD, Silveira RS et al. Opção e evasão de um curso de graduação em enfermagem: percepção de estudantes evadidos. Rev Gaúcha Enferm 2012 June;33(2):132-8.

22. Valle MJ. Prouni: política pública de acesso ao ensino superior ou privatização? Dissertação. Programa de PósGraduação Mestrado em Educação. Universidade Tuiuti do Paraná. Curitiba/PR, 2009.

23. Perbone JG, Carvalho EC. Sentimentos do estudante de enfermagem em seu primeiro contato com pacientes. Rev bras enferm. 2011Mar-Abr [acesso em 2013 ago 30]; 64 (2): 343-347. Disponível em: http://www.scielo.br/pdf/reben/v64n2/a19v64n2.pdf 24. Schmidt DRC, Dantas RAS, Marziale MHP. Ansiedade e depressão entre profissionais de enfermagem que atuam em blocos cirúrgicos. Revescenferm USP. 2011 [acesso em 2015 abr 16]; 45 (2): 487-93. Disponível em: http://www.scielo. $\mathrm{br} / \mathrm{pdf} / \mathrm{reeusp} / \mathrm{v} 45 \mathrm{n} 2 / \mathrm{v} 45 \mathrm{n} 2 \mathrm{a} 25 . \mathrm{pdf}$

25. Meira MDDM, Kurcgant P. O ensino de administração na graduação: percepção de enfermeiros egressos. Texto \& contexto enferm. 2009 Out-Dez [acesso em 2013 nov 08]; 18 (4): 670-679. Disponível em: http://www.scielo.br/pdf/tce/v18n4/08.pdf 26. Nunes CM, Tronchin DMR, Melleiro MM, Kurcgant P. Satisfação e insatisfação no trabalho na percepção de enfermeiros de um hospital universitário. Rev eletr enf 2010;12(2):252-7 


\section{Cristiane Aparecida Silveira Monteiro}

Endereço para correspondência - Av. Padre Francis Cletus Cox, n 1661, Jardim Country Club, CEP 37701-355, Poços de Caldas, MG, Brasil.

E-mail: casilve@yahoo.com.br

Lattes: http://lattes.cnpq.br/8840798305145545

Aline Graziele Firmino - aline@pucpcaldas.br

Daniela Aparecida Cruz Nascimento - danicruznascimento@hotmail.com

Josemara Mirelle da Silva - josemara_mirelly@hotmail.com

Enviado em 12 de fevereiro de 2015.

Aceito em 16 de julho de 2015. 
